\title{
Optimal Semiactive Damping Control for a Nonlinear Energy Sink Used to Stabilize Milling
}

\author{
Zhuo Chen (iD) and Huancai Lu (iD \\ Sound and Vibration Laboratory, College of Mechanical Engineering, Zhejiang University of Technology, 18 Chaowang Road, \\ Hangzhou 310014, China \\ Correspondence should be addressed to Huancai Lu; huancailu@zjut.edu.cn
}

Received 15 April 2020; Revised 15 September 2020; Accepted 15 October 2020; Published 30 October 2020

Academic Editor: M. Z. Naser

Copyright $(92020$ Zhuo Chen and Huancai Lu. This is an open access article distributed under the Creative Commons Attribution License, which permits unrestricted use, distribution, and reproduction in any medium, provided the original work is properly cited.

\begin{abstract}
Improving product quality of machining components has always met with problems due to the vibration of the milling machine's spindle, which can be reduced by adding a vibration absorber. The tuned vibration absorber (TVA) has been studied extensively and found to have a narrow bandwidth, but the cutting force possesses wide bandwidth in the process of machining parts. Introducing nonlinearity into the dynamic vibration absorber can effectively increase the bandwidth of vibration suppression and can significantly improve the robustness of the vibration absorber. In addition, a semiactive TVA has proved to be more effective than a passive TVA for many applications, so the main purpose of this study is to find some appropriate semiactive control methods for a nonlinear energy sink (NES), a nonlinear vibration absorber, in structural vibration applications. Two semiactive control methods are considered in this study: continuous groundhook damping control based on velocity and on-off groundhook damping control based on velocity. To fairly compare these vibration absorbers, the optimal parameters of a passive TVA, a passive NES, and two semiactive NESs are designed using numerical optimization techniques to minimize the root-mean-square acceleration. Two cutting forces are introduced in this study, a periodic force and an aperiodic force, and the four vibration absorbers are compared. When the primary structure is excited with aperiodic cutting force, the amplitude of the primary structure decreased by $17.73 \%$ with the passive TVA, by $72.29 \%$ with the passive NES, by $73.54 \%$ with the on-off NES, and by $87.54 \%$ with the continuous NES. When the primary structure is excited with periodic cutting force, the amplitude of the primary structure decreased by $49.01 \%$ with a passive TVA, by $86.93 \%$ with a passive NES, by $96.38 \%$ with an on-off NES, and by $99.23 \%$ with a continuous NES. The results show that the passive NES is better than the passive TVA; the semiactive NES provides more effective vibration attenuation than the passive NES, and the continuous control is more effective than the on-off control.
\end{abstract}

\section{Introduction}

A tuned vibration absorber (TVA) is a vibration absorbing device that is attached to a primary system to control vibration. It is usually composed of a mass, a linear stiffness, and a viscous damper. In 1909, Frahm [1] invented the first simple shock absorber. Then, Ormondroyd and Hartog [2] evolved it into a Voigt-type dynamic vibration absorber with damping. The passive TVA described above has simple structure but poor control effect, so the active TVA and semiactive TVA were successively studied by scholars. An active system can provide good performance, but it becomes more complex at the same time. Many problems arise such as the selection of sensors, power supply, weight constraints, stability, and robustness [3]. So, passive control and active control has been replaced by semiactive control for some applications $[4,5]$. A number of studies have introduced the advantages of semiactive control over passive control [6-14].

In the 1970s, Karnopp et al. [4] applied semiactive dampers to vehicle suspension systems, and the results showed that semiactive systems can provide many of the performance gains of active systems. Then, the variable damping system was proposed by Hrovat et al. [15], who studied a variable damping semiactive control applied to the suppression of wind-induced vibration of structures, and it also confirmed that semiactive TVA performed better than 
passive and active TVA. Four semiactive damping control laws [16] based on skyhook control and balance control are introduced, and the results show that they have better vibration suppression effects than the traditional passive control in the high frequency range. Koo et al. [17] introduced four semiactive control policies and optimized the parameters of a TVA according to them and then compared the transmissibility of the four systems and concluded that semiactive TVAs better reduce vibration. Ihsan et al. [18] used the root-mean-square value (RMS) of the acceleration as an indicator for evaluating the comfort of a car seat. Both skyhook and groundhook controls were developed. This paper mainly discusses groundhook control, which is divided into on-off groundhook control and continuous groundhook control. For on-off groundhook control, the damper is switched between two values, which are called onstate damping and off-state damping, as shown in Figure 1. Which state the damping is switched to is determined by the product of the relative velocity across the semiactive damper and the absolute velocity of the primary structure. For continuous groundhook control, the damping is not limited to just two values. It can change continuously between the two damping states, and the value is again determined by the velocity product. The figure shows the relationship between damping force and relative velocity of the primary structure and the absorber. It can be seen that $c_{\text {on }}$ and $c_{\text {off }}$ represent on-state damping and off-state damping, and $c$ represents passive damping.

In its simplest form, a nonlinear energy sink refers to a mass that is connected to the main structure by strongly nonlinear stiffness and viscous damping. Because linear dynamic vibration absorbers can effectively suppress vibration only when the excitation has narrow bandwidth, Roberson [19] points out that introducing nonlinearity into the dynamic vibration absorber can effectively increase the bandwidth of vibration suppression and can significantly improve the robustness of the vibration absorber. The passive NES has been studied by many scholars. Vakakis et al. [20] studied the response of a system with a linear oscillator coupled to a grounded nonlinear oscillator and found the phenomenon of targeted energy transfer. McFarland et al. [21] and Kerschen et al. [22] verified experimentally the phenomenon of targeted energy transfer and the existence of a threshold input energy to initiate effective TET. Zhang et al. [23] presented a new design for an NES which can realize vibration control and energy harvesting and realized efficient vibration control. Yao et al. [24] studied the vibration attenuation performance of the NES for the unbalanced rotor system and verified the NES has better performance over a wider frequency range than the linear absorber.

Milling is a widely employed material removal process, and many researchers have studied the effects of cutting parameters to improve the machining accuracy. Bolar et al. [25] studied feed per tooth, tool diameter, axial and radial depth of cut, and their influence on surface finish. Wang et al. [26] introduced a hybrid optimization method which can help users to find optimal cutting parameters, which provide better efficiency and lower power consumption for a milling process. Ding et al. [27] also studied the effects of cutting parameters on surface roughness in hard milling of AISI H13 steel.

As mentioned above, a semiactive TVA performs better than a passive TVA and a passive NES acts better than a passive TVA when the cutting force of the spindle possesses wide bandwidth. So, this paper investigates the vibration suppression effect of a semiactive nonlinear energy sink. By equipping the spindle of a milling machine with a passive TVA, a passive NES, and two semiactive NESs, the performance of these absorbers is evaluated. The performance index is the root-mean-square value of the acceleration of the primary structure (i.e., the spindle). Finally, the simulation results are analyzed and compared. This work provides new ideas about an NES application and the theoretical basis for the study of a semiactive nonlinear energy sink.

\section{Description of the Semiactive Control Methods}

In this section, two semiactive control methods are introduced. The ideal damping structural model is shown in Figure 2(a), where a passive damper is connected between the primary structure and the ground. The damper always applies to the main structure a force that is opposite to the direction of its velocity.

The semiactive control methods proposed imitate this model and generate a similar force. The equivalent model is shown in Figure 2(b). The state of the main structure and the NES are input to the controller, and then the damping coefficient can be adjusted. The difference between ideal damping model and equivalent damping model is that the damping force generated by $c_{\text {ground }}$ is replaced by that generated by $c_{\text {control }}$. These two models are derived from automobile suspension systems where semiactive control methods are used to reduce vibration of unsprung and sprung masses.

$m_{\mathrm{PS}}, c_{\mathrm{PS}}$, and $k_{\mathrm{PS}}$ are the mass, damping coefficient, and stiffness of the primary structure, respectively; $m_{\mathrm{NES}}$ and $k_{\mathrm{NES}}$ are the mass and stiffness of the NES; $c_{\text {ground }}$ is the damping coefficient of the groundhook damper; and $c_{\text {control }}$ is the controllable damping coefficient. $x_{\mathrm{PS}}$ and $x_{\mathrm{NES}}$ are the displacements of the two masses, and $\dot{x}_{\mathrm{PS}}$ and $\dot{x}_{\mathrm{NES}}$ are their velocities. $F$ is the excitation, a force which acts directly on the primary mass.

2.1. Continuous Groundhook Damping Control Based on Velocity. Now considering the ideal structural model, the damping force of $c_{\text {ground }}$ can be written as

$$
F_{\text {ground }}=c_{\text {ground }} \dot{x}_{\mathrm{PS}} \text {, }
$$

where $F_{\text {ground }}$ is the groundhook damping force. For the equivalent model, the controllable damping force can be written as

$$
F_{c}=c_{\text {control }}\left(\dot{x}_{\mathrm{PS}}-\dot{x}_{\mathrm{NES}}\right) \text {, }
$$

where $F_{c}$ is the equivalent damping force. In order for the damper to dissipate vibration energy, the product of the 


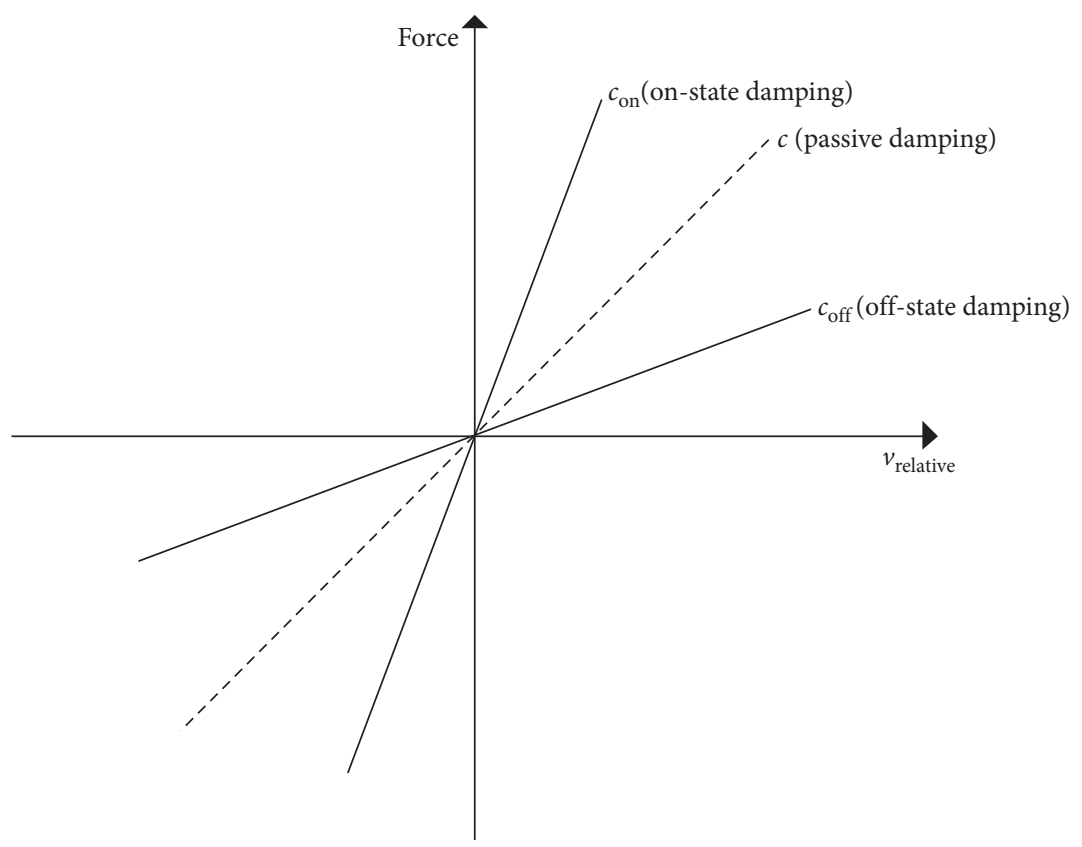

FIGURE 1: Damping force versus relative velocity.

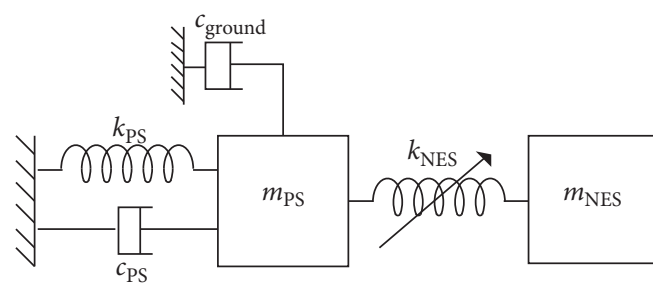

(a)

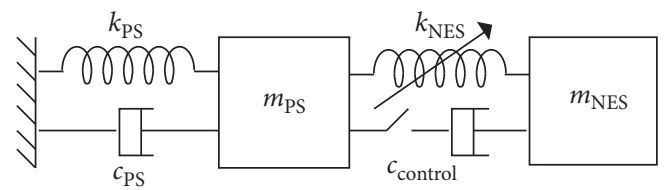

(b)

Figure 2: (a) Ideal damping model. (b) Equivalent damping model.

equivalent damping force $F_{c}$ and the relative velocity $\dot{x}_{\mathrm{PS}}-$ $\dot{x}_{\mathrm{NES}}$ must satisfy the inequality

$$
F_{c}\left(\dot{x}_{\mathrm{PS}}-\dot{x}_{\mathrm{NES}}\right) \geq 0 \text {. }
$$

Because $F_{c}$ is to emulate $F_{\text {ground }}$

$$
F_{c}=c_{\text {ground }} \dot{x}_{\mathrm{PS}} \text {. }
$$

Thus, the inequality can be derived

$$
\dot{x}_{\mathrm{PS}}\left(\dot{x}_{\mathrm{PS}}-\dot{x}_{\mathrm{NES}}\right) \geq 0 \text {. }
$$

The desired force is $c_{\text {ground }} \dot{x}_{\mathrm{PS}}$, but the semiactive damper can generate this force only when $\dot{x}_{\mathrm{PS}}$ and $\dot{x}_{\mathrm{PS}}-\dot{x}_{\mathrm{NES}}$ have the same sign. Otherwise, the semiactive damper can provide only a force opposite to the desired force, in which case it is better to let the damping force be zero. The continuous semiactive groundhook control algorithm is thus given by

$$
F_{c}= \begin{cases}c_{\text {ground }} \dot{x}_{\mathrm{PS}}, & \dot{x}_{\mathrm{PS}}\left(\dot{x}_{\mathrm{PS}}-\dot{x}_{\mathrm{NES}}\right) \geq 0, \\ 0, & \dot{x}_{\mathrm{PS}}\left(\dot{x}_{\mathrm{PS}}-\dot{x}_{\mathrm{NES}}\right)<0 .\end{cases}
$$

Setting equation (2) equal to equation (6) when possible, $c_{\text {control }}$ can be expressed as

$$
c_{\text {control }}= \begin{cases}\frac{c_{\text {ground }} \dot{x}_{\mathrm{PS}}}{\dot{x}_{\mathrm{PS}}-\dot{x}_{\mathrm{NES}}}, & \dot{x}_{\mathrm{PS}}\left(\dot{x}_{\mathrm{PS}}-\dot{x}_{\mathrm{NES}}\right) \geq 0, \\ 0, & \dot{x}_{\mathrm{PS}}\left(\dot{x}_{\mathrm{PS}}-\dot{x}_{\mathrm{NES}}\right)<0 .\end{cases}
$$

It is obvious that $c_{\text {control }}$ will tend to infinity when the relative velocity $\dot{x}_{\mathrm{PS}}-\dot{x}_{\mathrm{NES}}$ is very small, so there must be both an upper bound and a lower bound. The damping coefficient in equation (7) is therefore rewritten as

$c_{\text {control }}= \begin{cases}\max \left[0, \min \left(\frac{c_{\text {ground }} \dot{x}_{\mathrm{PS}}}{\dot{x}_{\mathrm{PS}}-\dot{x}_{\mathrm{NES}}}, c_{\text {max }}\right)\right], & \dot{x}_{\mathrm{PS}}\left(\dot{x}_{\mathrm{PS}}-\dot{x}_{\mathrm{NES}}\right) \geq 0, \\ 0, & \dot{x}_{\mathrm{PS}}\left(\dot{x}_{\mathrm{PS}}-\dot{x}_{\mathrm{NES}}\right)<0 .\end{cases}$

Equation (8) is the continuous groundhook damping control based on velocity.

2.2. On-Off Groundhook Damping Control Based on Velocity. To simplify equation (8), an on-off groundhook control law is proposed, given by 


$$
F_{c}= \begin{cases}c_{\max }\left(\dot{x}_{\mathrm{PS}}-\dot{x}_{\mathrm{NES}}\right), & \dot{x}_{\mathrm{PS}}\left(\dot{x}_{\mathrm{PS}}-\dot{x}_{\mathrm{NES}}\right) \geq 0, \\ 0, & \dot{x}_{\mathrm{PS}}\left(\dot{x}_{\mathrm{PS}}-\dot{x}_{\mathrm{NES}}\right)<0,\end{cases}
$$

where $c_{\max }$ is the on-state damping constant of the on-off damper. Setting equation (2) equal to the first case in equation (9), $c_{\text {control }}$ can be expressed as

$$
c_{\text {control }}= \begin{cases}c_{\text {max }}, & \dot{x}_{\mathrm{PS}}\left(\dot{x}_{\mathrm{PS}}-\dot{x}_{\mathrm{NES}}\right) \geq 0, \\ 0, & \dot{x}_{\mathrm{PS}}\left(\dot{x}_{\mathrm{PS}}-\dot{x}_{\mathrm{NES}}\right)<0 .\end{cases}
$$

Equation (10) is the on-off groundhook control based on velocity. Equations (1)-(10) are derived from reference [12].

\section{Numerical Models}

In this section, a passive TVA, a passive NES, and a semiactive groundhook equivalent NES are introduced. Figure 3(a) shows a 2-DOF system with a passive TVA, Figure 3 (b) shows a 2-DOF system with a passive NES, and Figure 2(b) shows the groundhook equivalent NES configuration.

The equations of motion of the passive TVA model can be written as

$$
\begin{array}{r}
m_{\mathrm{PS}} \ddot{x}_{\mathrm{PS}}+c_{\mathrm{PS}} \dot{x}_{\mathrm{PS}}+k_{\mathrm{PS}} x_{\mathrm{PS}}+c_{\mathrm{TVA}}\left(\dot{x}_{\mathrm{PS}}-\dot{x}_{\mathrm{TVA}}\right)+k_{\mathrm{TVA}}\left(x_{\mathrm{PS}}-x_{\mathrm{TVA}}\right)=F, \\
m_{\mathrm{TVA}} \ddot{x}_{\mathrm{TVA}}+c_{\mathrm{TVA}}\left(\dot{x}_{\mathrm{TVA}}-\dot{x}_{\mathrm{PS}}\right)+k_{\mathrm{TVA}}\left(x_{\mathrm{TVA}}-x_{\mathrm{PS}}\right)=0 .
\end{array}
$$

In addition, those of the passive NES model can be written as

$$
\begin{array}{r}
m_{\mathrm{PS}} \ddot{x}_{\mathrm{PS}}+c_{\mathrm{PS}} \dot{x}_{\mathrm{PS}}+k_{\mathrm{PS}} x_{\mathrm{PS}}+c_{\mathrm{NES}}\left(\dot{x}_{\mathrm{PS}}-\dot{x}_{\mathrm{NES}}\right)+k_{\mathrm{NES}}\left(x_{\mathrm{PS}}-x_{\mathrm{NES}}\right)^{3}=F \\
m_{\mathrm{NES}} \ddot{x}_{\mathrm{NES}}+c_{\mathrm{NES}}\left(\dot{x}_{\mathrm{NES}}-\dot{x}_{\mathrm{PS}}\right)+k_{\mathrm{NES}}\left(x_{\mathrm{NES}}-x_{\mathrm{PS}}\right)^{3}=0 .
\end{array}
$$

The difference between the passive TVA and the passive NES is that the passive NES has a cubic stiffness.
The equations of motion of the groundhook equivalent NES configuration are

$$
\begin{array}{r}
m_{\mathrm{PS}} \ddot{x}_{\mathrm{PS}}+c_{\mathrm{PS}} \dot{x}_{\mathrm{PS}}+k_{\mathrm{PS}} x_{\mathrm{PS}}+c_{\mathrm{control}}\left(\dot{x}_{\mathrm{PS}}-\dot{x}_{\mathrm{NES}}\right)+k_{\mathrm{NES}}\left(x_{\mathrm{PS}}-x_{\mathrm{NES}}\right)^{3}=F, \\
m_{\mathrm{NES}} \ddot{x}_{\mathrm{NES}}+c_{\mathrm{control}}\left(\dot{x}_{\mathrm{NES}}-\dot{x}_{\mathrm{PS}}\right)+k_{\mathrm{NES}}\left(x_{\mathrm{NES}}-x_{\mathrm{PS}}\right)^{3}=0,
\end{array}
$$

where $c_{\text {control }}$ is replaced by either of the two semiactive control methods during numerical simulation. The difference between the passive NES and the semiactive NES is that the damping coefficient of the semiactive NES changes according to the state of the system.

There are two kinds of cutting force to input. The aperiodic force [19] is shown in Figure 4(a) and its wavelet transform in Figure 5. From 0 s to $0.5 \mathrm{~s}$, the frequency of the excitation changes linearly from $300 \mathrm{~Hz}$ to $200 \mathrm{~Hz}$ during the initial engagement of the cutting process; from $0.5 \mathrm{~s}$ to $1.5 \mathrm{~s}$, the frequency remains at $200 \mathrm{~Hz}$, which is the steady cutting state; and from $1.5 \mathrm{~s}$ to $2 \mathrm{~s}$, the frequency of the excitation changes linearly from $200 \mathrm{~Hz}$ to $300 \mathrm{~Hz}$ during disengagement from the workpiece.

The periodic cutting force [28] is shown in Figure 6. There are two stages within each cycle, which are cutting and noncutting. The period is $0.005 \mathrm{~s}$, and the main frequency is $200 \mathrm{~Hz}$. The purpose of the wavelet transform is to visually depict the variation of frequency components of the cutting force with time.
The parameters of the system are shown in Table 1 . The primary structure mass, stiffness, and damping and the absorber mass are fixed; the stiffness and damping coefficient of the absorbers are to be optimized.

\section{Optimization}

This section describes the performance of the two semiactive NESs and compares both of them with the passive NES. Also, the passive NES is compared with the passive TVA. In order to evaluate every vibration absorber fairly, relevant parameters of each are optimized: the damping of the TVA $\left(c_{\mathrm{TVA}}\right)$, the stiffness of the TVA $\left(k_{\mathrm{TVA}}\right)$; the damping of the passive NES $\left(c_{\mathrm{NES}}\right)$, the stiffness of the passive NES $\left(k_{\mathrm{NES}}\right)$; the on-state damping of the on-off NES $\left(c_{\max }\right)$, the stiffness of the on-off NES $\left(k_{\mathrm{NES}}\right)$; the damping coefficient of the groundhook damper of the continuous NES ( $\left.c_{\text {ground }}\right)$, the stiffness of the continuous NES $\left(k_{\mathrm{NES}}\right)$, and the upper damping bound of the continuous NES $\left(c_{\max }\right)$. During the optimization process, a multidimensional nonlinear 


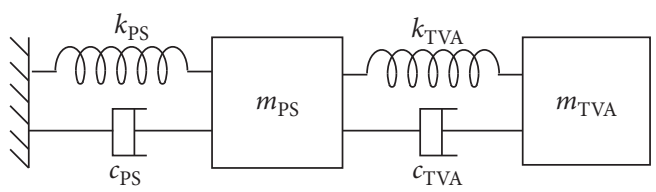

(a)

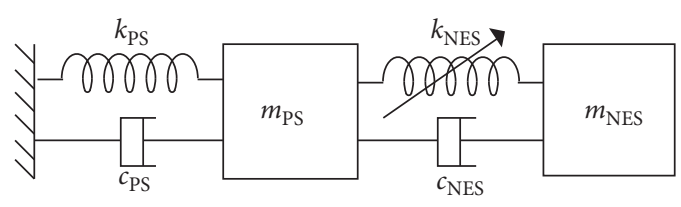

(b)

Figure 3: (a) Passive TVA model. (b) Passive NES model.

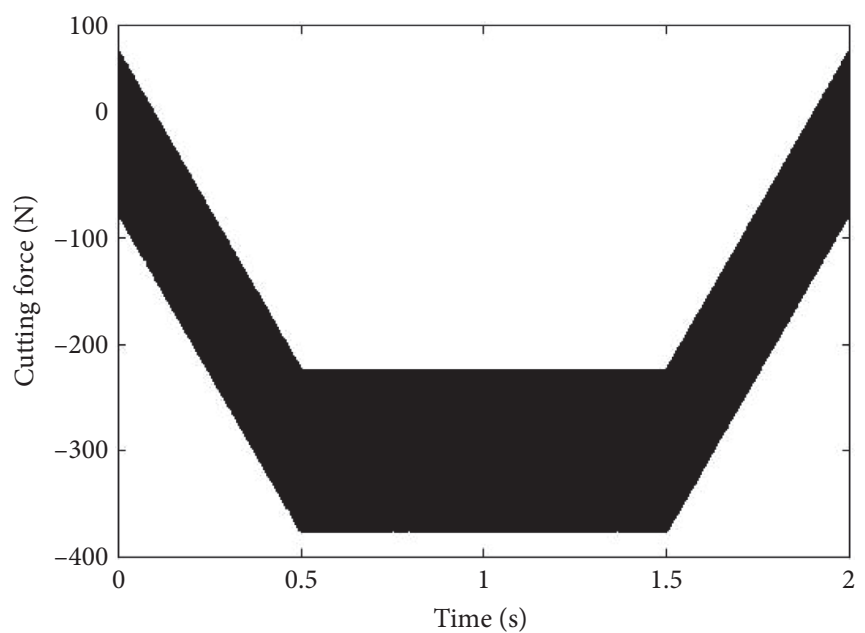

(a)

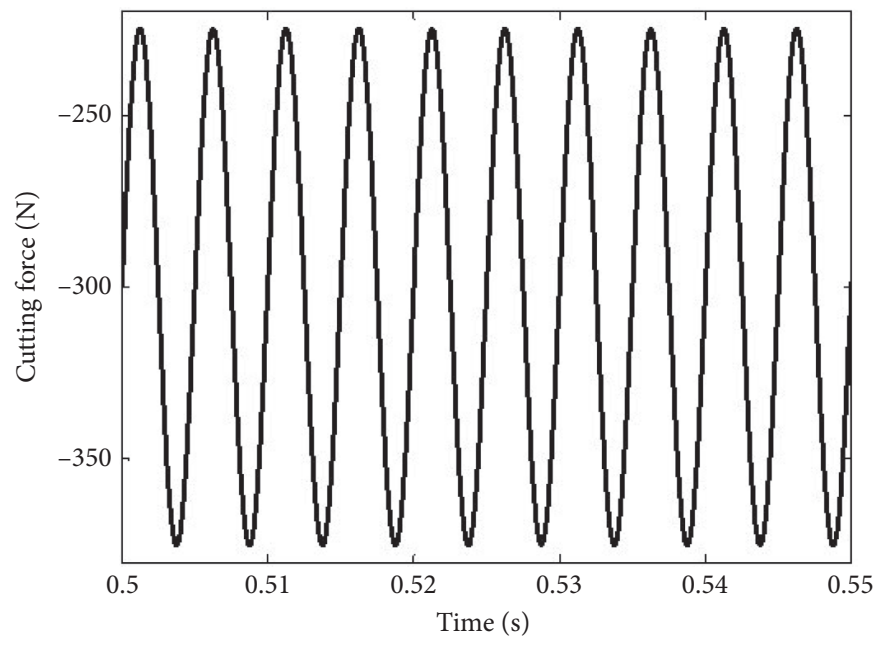

(c)

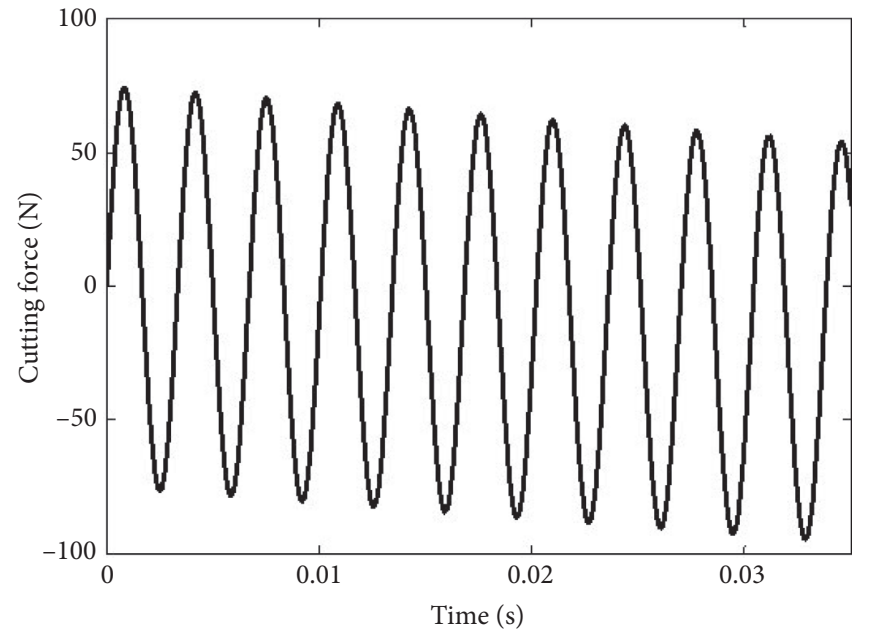

(b)

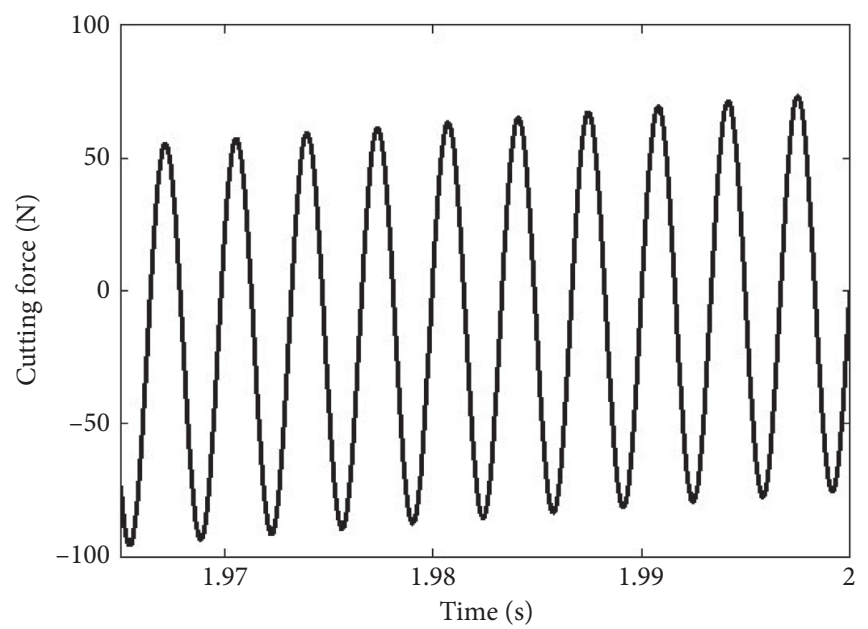

(d)

Figure 4: (a) Cutting force. (b) 0 to $0.035 \mathrm{~s}$ of the force. (c) $0.5 \mathrm{~s}$ to $0.55 \mathrm{~s}$ of the force. (d) $1.965 \mathrm{~s}$ to $2 \mathrm{~s}$ of the force.

constrained minimization function called "globalsearch.m (fmincon.m)" in the Matlab optimization toolbox is used. The "fmincon.m" is more likely to find a local minimum, but "globalsearch.m" can locate the global minimum.

4.1. Optimization Routine. The optimization process composed of three steps. The first step is to define the system parameters, and the second step is to set initial values and ranges of parameters to be optimized in the simulation. The initial values of the parameters and their ranges for the optimization are summarized in Table 2. The most important part of the optimization progress is calculating the objective function, defined here as

$$
J=\operatorname{RMS}\left(\ddot{x}_{1}\right)=\sqrt{\frac{\sum_{n=1}^{N}\left(\ddot{x}_{1}(n)\right)^{2}}{N}} .
$$

The minimum value of the objective function is returned along with the corresponding optimal parameters. 


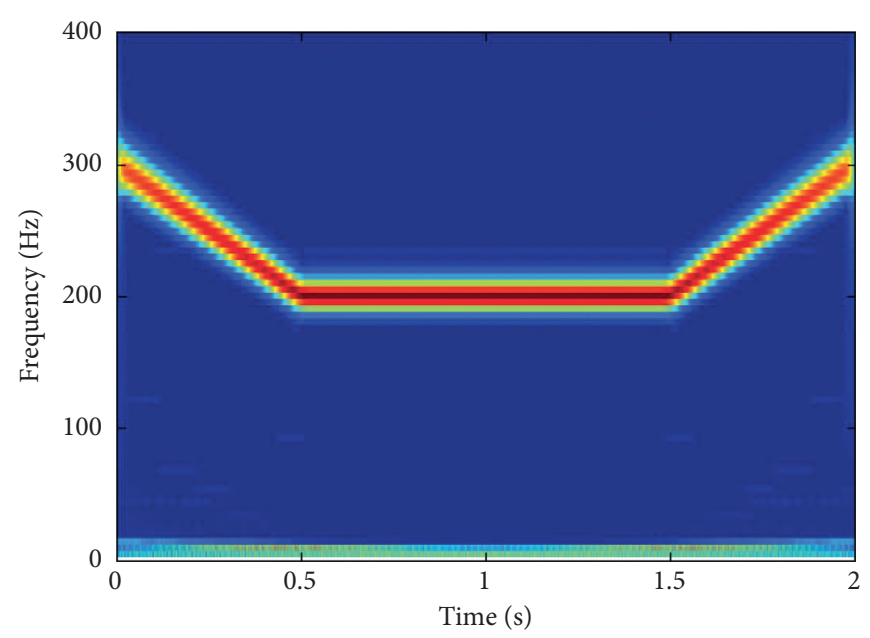

Figure 5: Wavelet transform of the excitation.

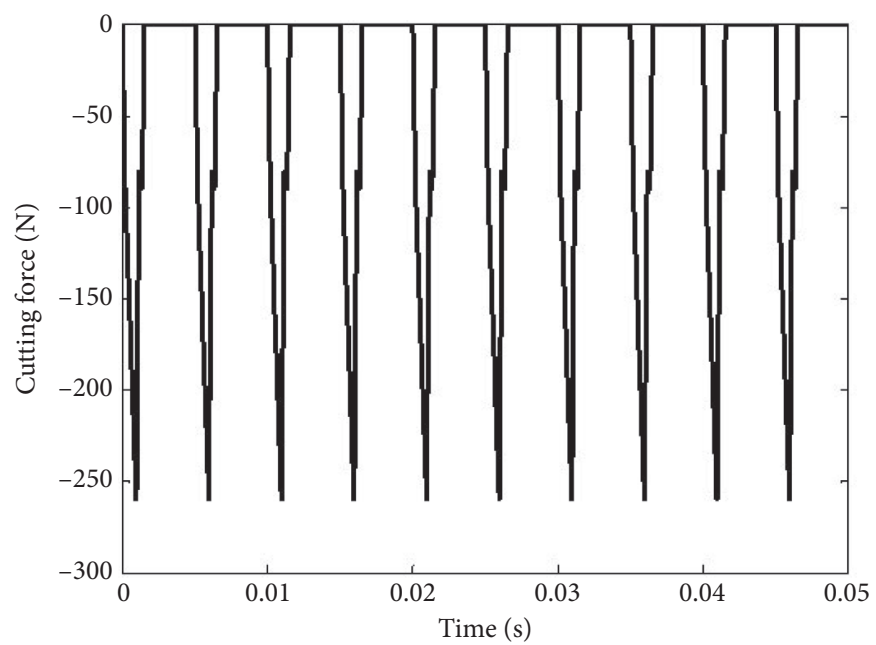

(a)

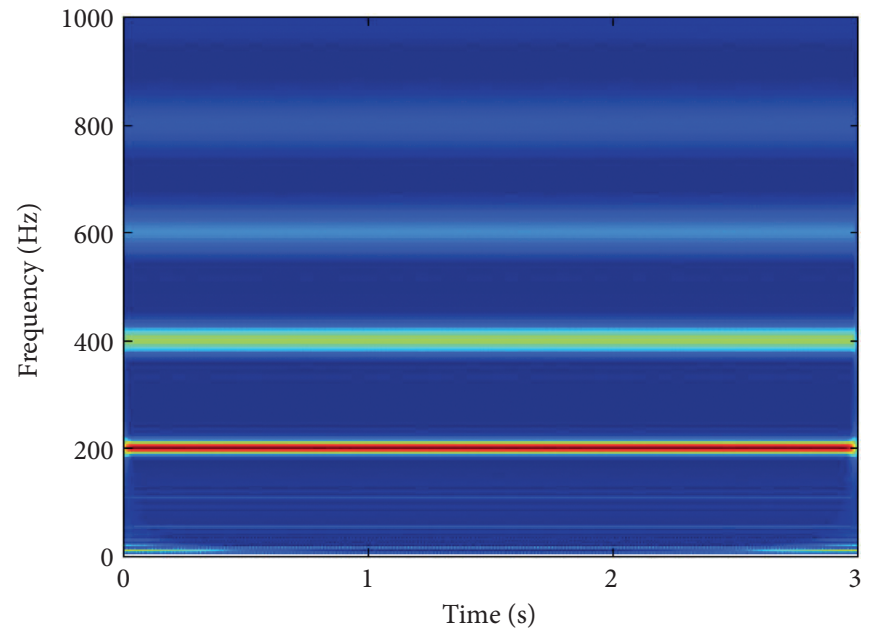

(b)

Figure 6: (a) Cutting force. (b) Wavelet transform of excitation. 
TABLE 1: System parameters.

\begin{tabular}{lr}
\hline Parameter & Value \\
\hline Primary structure mass $\left(m_{\mathrm{PS}}\right)$ & $20 \mathrm{~kg}$ \\
TVA and NES mass $\left(m_{\mathrm{TVA}}\right.$ and $\left.m_{\mathrm{NES}}\right)$ & $2.5 \mathrm{~kg}$ \\
Primary structure stiffness $\left(k_{\mathrm{PS}}\right)$ & $72000 \mathrm{~N} / \mathrm{m}$ \\
Primary structure damping $\left(c_{\mathrm{PS}}\right)$ & $10 \mathrm{Ns} / \mathrm{m}$ \\
\hline
\end{tabular}

TABLE 2: Initial values and parameter ranges for optimization.

\begin{tabular}{lcrr}
\hline Model & Parameter & Initial value & Parameter range \\
\hline \multirow{2}{*}{ Passive TVA } & $c_{\text {TVA }}(\mathrm{Ns} / \mathrm{m})$ & 0.1 & $0.1 \leq c_{\mathrm{TVA}} \leq 1000$ \\
& $k_{\mathrm{TVA}}(\mathrm{N} / \mathrm{m})$ & $1 \times 10^{6}$ & $1 \times 10^{5} \leq k_{\mathrm{TVA}} \leq 1 \times 10^{7}$ \\
\hline \multirow{2}{*}{ Passive NES } & $c_{\mathrm{NES}}(\mathrm{Ns} / \mathrm{m})$ & 0.1 & $0.1 \leq c_{\mathrm{NES}} \leq 1000$ \\
& $k_{\mathrm{NES}}\left(\mathrm{N} / \mathrm{m}^{3}\right)$ & $1 \times 10^{6}$ & $1 \times 10^{5} \leq k_{\mathrm{NES}} \leq 1 \times 10^{7}$ \\
\hline \multirow{2}{*}{ On-off NES } & $c_{\max }(\mathrm{Ns} / \mathrm{m})$ & 0.1 & $0.1 \leq c_{\max } \leq 1000$ \\
& $k_{\mathrm{NES}}\left(\mathrm{N} / \mathrm{m}^{3}\right)$ & $1 \times 10^{6}$ & $1 \times 10^{5} \leq k_{\mathrm{NES}} \leq 1 \times 10^{7}$ \\
\hline \multirow{2}{*}{ Continuous NES } & $c_{\max }\left(\mathrm{Ns} / \mathrm{m}^{3}\right)$ & 0.1 & $0.1 \leq c_{\max } \leq 1000$ \\
& $c_{\text {ground }}\left(\mathrm{Ns} / \mathrm{m}^{3}\right)$ & 0.1 & $0.1 \leq c_{\text {ground }} \leq 1000$ \\
& $k_{\mathrm{NES}}\left(\mathrm{N} / \mathrm{m}^{3}\right)$ & $1 \times 10^{6}$ & $1 \times 10^{5} \leq k_{\mathrm{NES}} \leq 1 \times 10^{7}$ \\
\hline
\end{tabular}

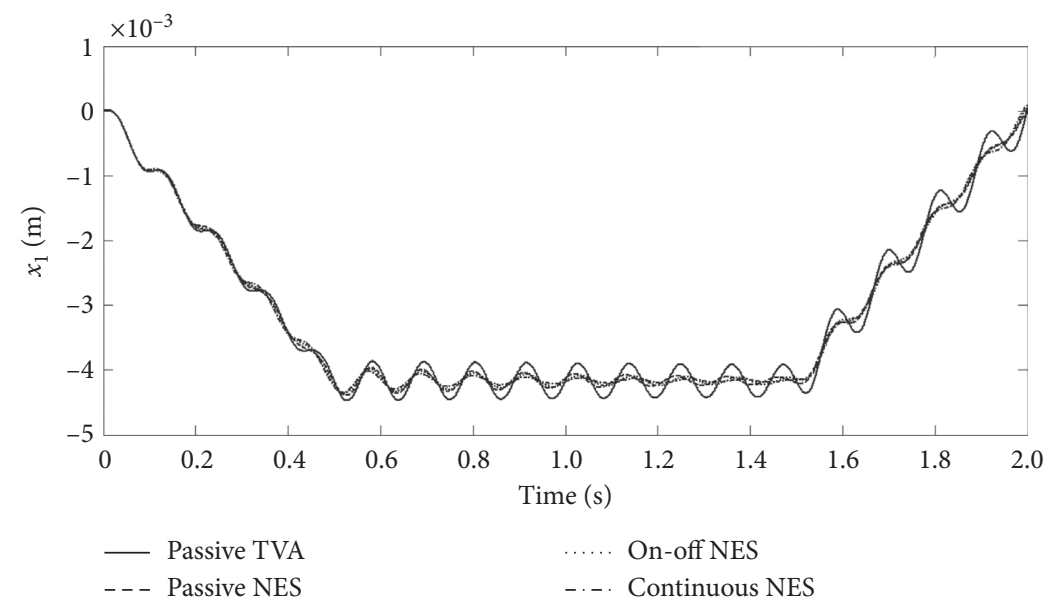

FIGURE 7: Displacement of main structure.

\subsection{Optimization Results}

4.2.1. Optimal Results with the Aperiodic Cutting Force. The displacement of the primary structure (i.e., the spindle) of every optimal system is shown in Figure 7, from which we can see the amplitude of displacement with a semiactive NES attenuates faster than that with a passive NES, and the amplitude of displacement with a passive NES also attenuates faster than that with a passive TVA during the steady cutting stage. During steady cutting, the amplitude of the primary structure decreased by $17.73 \%$ with the passive TVA, by $72.29 \%$ with the passive NES, by $73.54 \%$ with the on-off NES, and by $87.54 \%$ with the continuous NES. During the initial engagement of the cutting process and the final disengagement, the amplitude of the spindle with the passive TVA is larger than that with the passive NES and that with the passive NES is larger than that with the semiactive NES. The optimal parameters are summarized in Table 3.
The semiactive damping of the on-off NES is shown in Figure 8(a) while Figure 8(b) shows the semiactive damping of the continuous NES.

To verify the optimization results, the accelerations of the main structure versus the stiffness of the TVA and the damping coefficient of the TVA were plotted. For example, Figure 9(a) shows the relation of the three variables for the system with a passive TVA. In order to see the minimum value more clearly, Figure 9(b) magnifies the region near the minimum. The corresponding damping $\mathcal{c}_{\text {TVA-opt }}$, stiffness $k_{\text {TVA-opt }}$, and acceleration are $160 \mathrm{Ns} / \mathrm{m}, 8.4 \times 10^{6} \mathrm{~N} / \mathrm{m}$, and $2.07 \mathrm{~m} / \mathrm{s}^{2}$, respectively.

4.2.2. Optimal Results with the Periodic Cutting Force. The displacement of the primary structure of every optimal system is shown in Figure 10, from which we can see the displacements of main structures with semiactive NESs 
TABLE 3: Summary of optimal parameters obtained with the periodic cutting force.

\begin{tabular}{|c|c|c|c|}
\hline Passive TVA & Passive NES & On-off NES & Continuous NES \\
\hline$k_{\text {TVA-opt }} 8.41 \times 10^{6} \mathrm{~N} / \mathrm{m}$ & $k_{\mathrm{NES}-\mathrm{opt}} 9.98 \times 10^{6} \mathrm{~N} / \mathrm{m}^{3}$ & $k_{\mathrm{NES}-\mathrm{opt}} 9.90 \times 10^{6} \mathrm{~N} / \mathrm{m}^{3}$ & $k_{\mathrm{NES}-\mathrm{opt}} 1 \times 10^{7} \mathrm{~N} / \mathrm{m}^{3}$ \\
\hline$c_{\text {TVA-opt }} 171.05 \mathrm{Ns} / \mathrm{m}$ & $c_{\text {TVA-opt }} 106.90 \mathrm{Ns} / \mathrm{m}$ & $c_{\max -\text { opt }} 999.01 \mathrm{Ns} / \mathrm{m}$ & $c_{\max -\mathrm{opt}} 999.01 \mathrm{Ns} / \mathrm{m}$ \\
\hline $\mathrm{N} / \mathrm{A}$ & $\mathrm{N} / \mathrm{A}$ & $\mathrm{N} / \mathrm{A}$ & $c_{\text {ground-opt }} 999.01 \mathrm{Ns} / \mathrm{m}$ \\
\hline
\end{tabular}

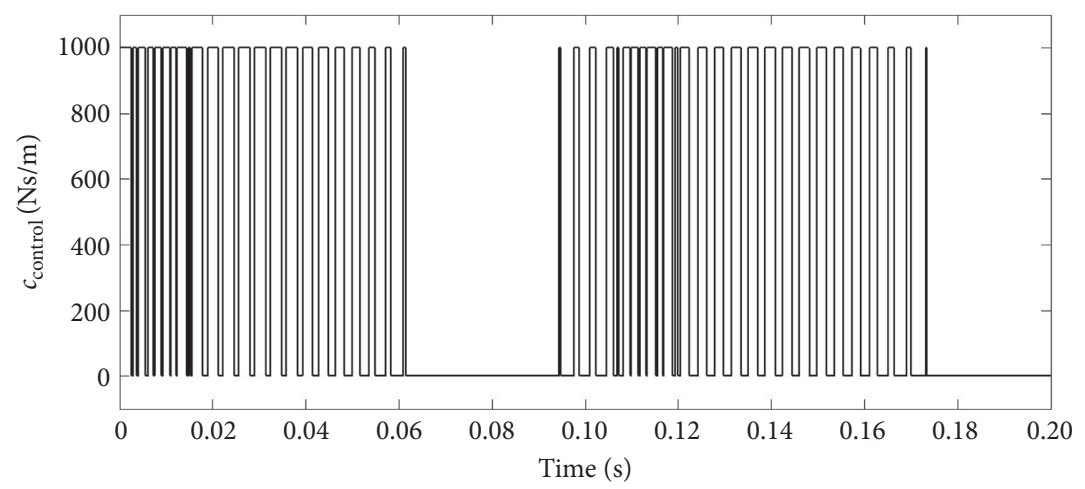

(a)

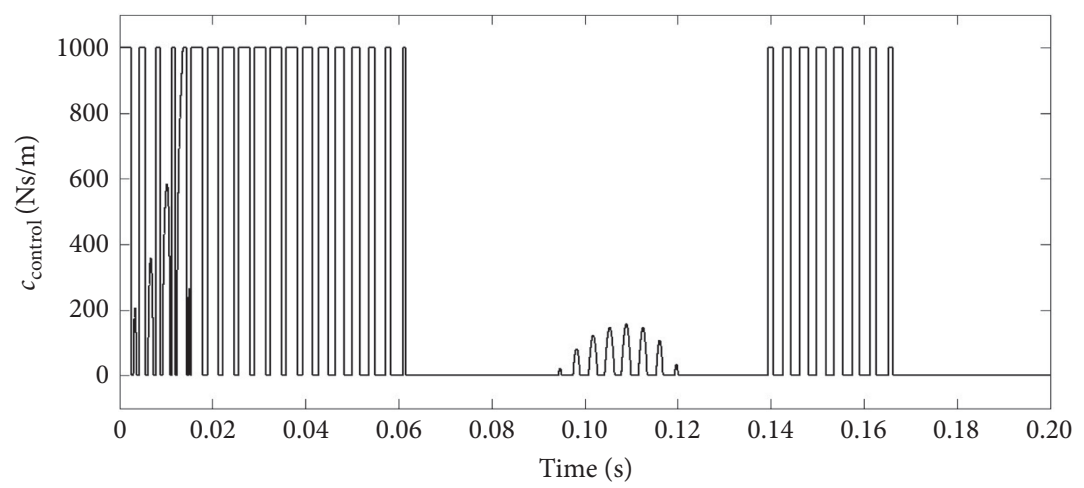

(b)

Figure 8: (a) Semiactive damping of on-off NES. (b) Semiactive damping of continuous NES.

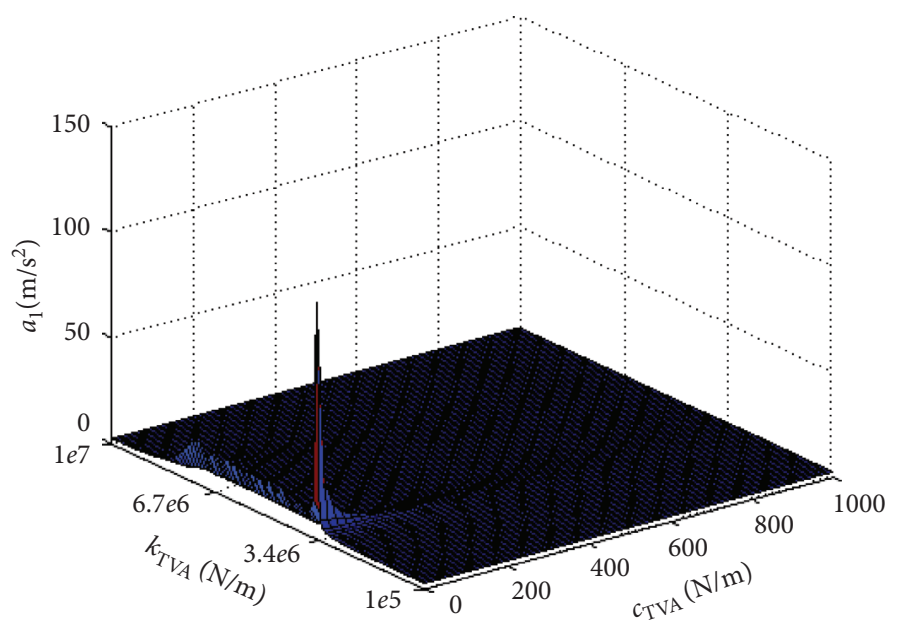

(a)

FIgURE 9: Continued. 


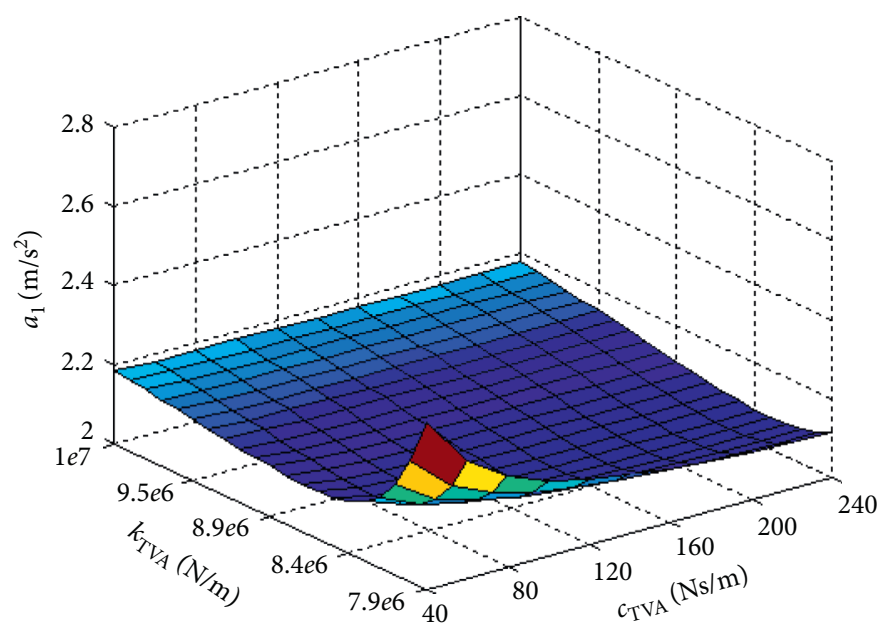

(b)

FIgURE 9: RMS $\left(a_{1}\right)$ versus $k_{\mathrm{TVA}}$ and $c_{\mathrm{TVA}}$. (a) Global plot. (b) Local plot.

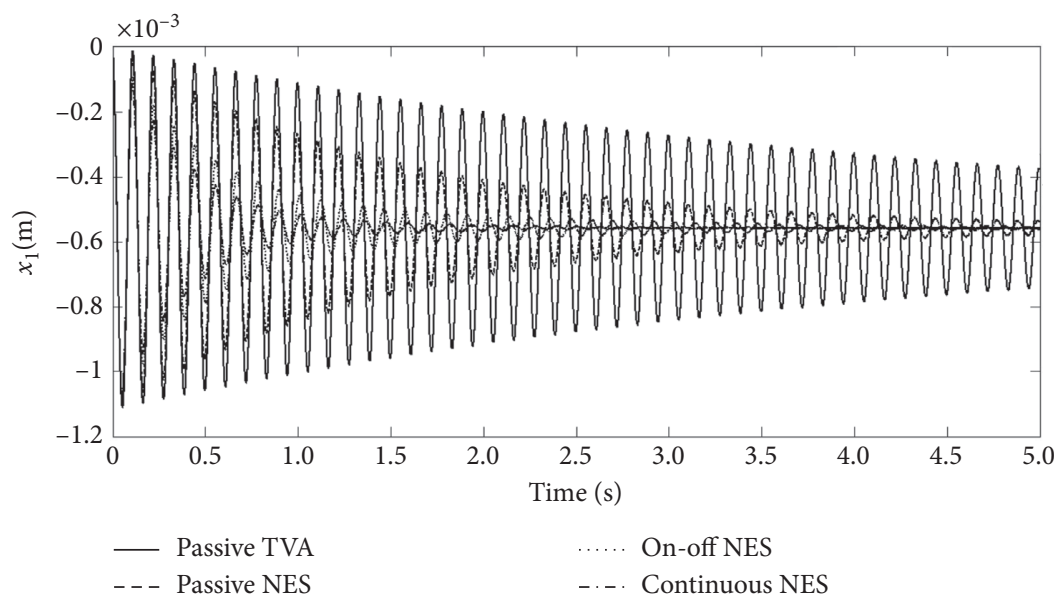

Figure 10: Displacement of main structure.

TABLE 4: Summary of optimal parameters obtained with the periodic cutting force.

\begin{tabular}{lccc}
\hline Passive TVA & Passive NES & On-off NES & Continuous NES \\
\hline$k_{\text {TVA-opt }} 3.96 \times 10^{6} \mathrm{~N} / \mathrm{m}$ & $k_{\text {NES-opt }} 1 \times 10^{7} \mathrm{~N} / \mathrm{m}^{3}$ & $k_{\mathrm{NES}-\mathrm{opt}} 4.24 \times 10^{6} \mathrm{~N} / \mathrm{m}^{3}$ & $k_{\mathrm{NES}-\mathrm{opt}} 7.82 \times 10^{6} \mathrm{~N} / \mathrm{m}^{3}$ \\
$c_{\text {TVA-opt }} 31.00 \mathrm{Ns} / \mathrm{m}$ & $c_{\text {NES-opt }} 999.01 \mathrm{Ns} / \mathrm{m}$ & $c_{\text {max-opt }} 999.01 \mathrm{Ns} / \mathrm{m}$ & $c_{\text {max-opt }} 911.84 \mathrm{Ns} / \mathrm{m}$ \\
N/A & N/A & N/A & $c_{\text {ground-opt }} 999.01 \mathrm{Ns} / \mathrm{m}$ \\
\hline
\end{tabular}

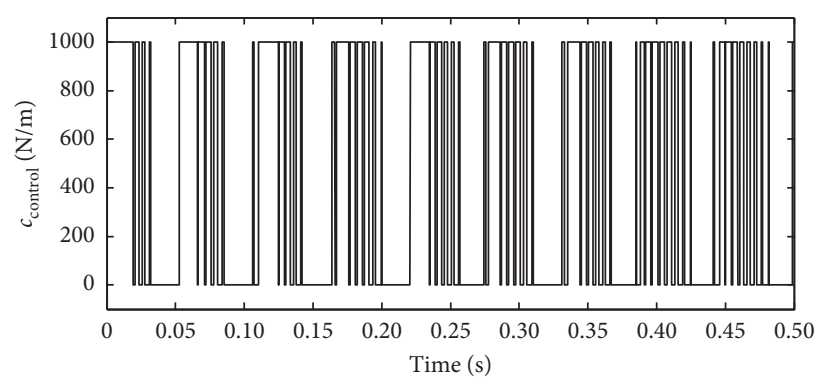

(a)

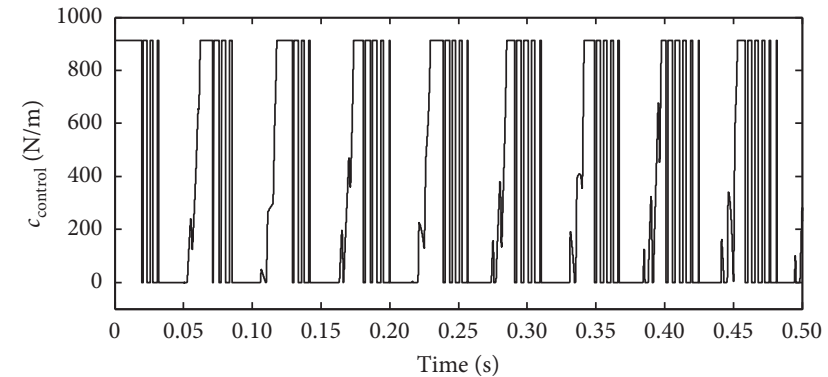

(b)

Figure 11: (a) Semiactive damping of on-off NES. (b) Semiactive damping of continuous NES. 
attenuate faster than that with a passive NES. Furthermore, the displacements of primary structures with NESs attenuate faster than that with a TVA.

Within three seconds, the amplitude of the primary structure decreased by $49.01 \%$ with a passive TVA, by $86.93 \%$ with a passive NES, by $96.38 \%$ with an on-off NES, and by $99.23 \%$ with a continuous NES. The optimal parameters are summarized in Table 4. The semiactive damping of the NESs is shown in Figure 11.

The control methods in this study come from the existing research, and the optimization routine comes from Koo et al.'s [17] research. The results in this study are reliable because the results from Koo et al.'s research have been reproduced with the same mechanisms. The analytic solutions are not easy to get, so there will be further study about semiactive NES.

\section{Conclusions}

In this study, systems based on a passive TVA, a passive NES, and two semiactive NESs are compared. The two semiactive control policies are on-off groundhook control based on velocity and continuous groundhook control based on velocity. We compare the performance of the passive TVA, the passive NES, and the semiactive NESs using parameters optimized to reduce the root-mean-square acceleration of the primary structure (spindle). When the primary structure is excited with an aperiodic cutting force, the amplitude of the primary structure decreased by $17.73 \%$ with the passive TVA, by $72.29 \%$ with the passive NES, by $73.54 \%$ with the on-off NES, and by $87.54 \%$ with the continuous NES. When the primary structure is excited with periodic cutting force, the amplitude of the primary structure decreased by $49.01 \%$ with a passive TVA, by $86.93 \%$ with a passive NES, by $96.38 \%$ with an on-off NES, and by $99.23 \%$ with a continuous NES. The results indicate that the semiactive NES performs better than the passive NES, and the passive NES performs better than the passive TVA. Further analysis shows that the continuous NES performs better than the onoff NES. As shown in this study, the conclusions are valid when the system is excited by two completely different cutting forces, which means the methods have good robustness.

\section{Data Availability}

The data used to support the findings of this study are available from the corresponding author upon request.

\section{Conflicts of Interest}

The authors declare that there are no conflicts of interest regarding the publication of this paper.

\section{Acknowledgments}

This work was supported by the Ministry of Science and Technology, China (grant no. 2017YFC0306202), National
Natural Science Foundation of China (grant no. 51975525), and Zhejiang University of Technology-Institute of Applied Physics, Russian Academy of Sciences Joint Research Laboratory of Innovative Technology of Acoustics and Vibration (grant no. 2018C04018).

\section{References}

[1] H. Frahm, "Device for damping vibrations of bodies," US patent 989958, 1909.

[2] J. Ormondroyd and D. Hartog, "The theory of the dynamical vibration absorber," ASME Journal of Applied Mechanics, vol. 49, pp. 9-22, 1928.

[3] M. A. Franchek, M. W. Ryan, and R. J. Bernhard, "Adaptive passive vibration control," Journal of Sound and Vibration, vol. 189, no. 5, pp. 565-585, 1996.

[4] D. Karnopp, M. J. Crosby, and R. A. Harwood, "Vibration control using semi-active force generators," Journal of Engineering for Industry, vol. 96, no. 2, pp. 619-626, 1974.

[5] M. J. Crosby and D. C. Karnopp, "The active damper: a new concept for shock and vibration control," Shock and Vibration Bulletin, vol. 43, pp. 119-133, 1973.

[6] S. Rakheja and S. Sankar, "Vibration and shock isolation performance of a semi-active "on-off" damper," Journal of Vibration and Acoustics, vol. 107, no. 4, pp. 398-403, 1985.

[7] J. Alanoly and S. Sankar, "A new concept in semi-active vibration isolation," Journal of Mechanisms, Transmissions, and Automation in Design, vol. 109, no. 2, pp. 242-247, 1987.

[8] L. R. Miller, "Tuning passive, semi-active, and fully active suspension systems," in Proceedings of the 27th Conference on Decision and Control, Austin, TX, USA, 1988.

[9] X. Wu and M. J. Griffin, "A semi-active control policy to reduce the occurrence and severity of end-stop impacts in a suspension seat with an electrorheological fluid damper," Journal of Sound and Vibration, vol. 203, no. 5, pp. 781-793, 1997.

[10] L. M. Jansen and S. J. Dyke, "Semi-active control strategies for MR dampers: a comparative study," Journal of Engineering Mechanics, vol. 126, no. 8, pp. 795-803, 2000.

[11] J.-S. Oh, Y.-J. Shin, H.-W. Koo, H.-C. Kim, J. Park, and S.-B. Choi, "Vibration control of a semi-active railway vehicle suspension with magneto-rheological dampers," Advances in Mechanical Engineering, vol. 8, no. 4, pp. 1-13, 2016.

[12] H. Garrido, O. Curadelli, and D. Ambrosini, "Control of relative vibration between flexible appendages using passive and semi-active isolation," Engineering Structures, vol. 152, pp. 819-831, 2017.

[13] S. Segla and M. Musil, "Comparison of passive and semiactive horizontal platform suspensions," Tehnički Vjesnik, vol. 25, no. 6, pp. 1659-1666, 2018.

[14] D. H. Zelleke and V. A. Matsagar, "Semi-active algorithm for energy-based predictive structural control using tuned mass dampers," Computer-Aided Civil and Infrastructure Engineering, vol. 34, no. 11, pp. 1-16, 2019.

[15] D. Hrovat, P. Barak, and M. Rabins, "Semi-active versus passive or active tuned mass dampers for structural control," Journal of Engineering Mechanics, vol. 109, no. 3, pp. 691-705, 1983.

[16] Y. Liu, T. P. Waters, and M. J. Brennan, “A comparison of semi-active damping control strategies for vibration isolation of harmonic disturbances," Journal of Sound and Vibration, vol. 280, no. 1-2, pp. 21-39, 2005.

[17] J.-H. Koo, M. Ahmadian, M. Setareh, and T. Murray, "In search of suitable control methods for semi-active tuned 
vibration absorbers," Journal of Vibration and Control, vol. 10, no. 2, pp. 163-174, 2004.

[18] S. I. Ihsan, M. Ahmadian, W. F. Faris, and E. D. Blancard, "Ride performance analysis of half-car model for semi-active system using RMS as performance criteria," Shock and Vibration, vol. 16, no. 6, pp. 593-605, 2009.

[19] R. E. Roberson, "Synthesis of a nonlinear dynamic vibration absorber," Journal of the Franklin Institute, vol. 254, no. 5, pp. 205-220, 1952.

[20] A. F. Vakakis, L. I. Manevitch, O. Gendelman, and L. Bergman, "Dynamics of linear discrete systems connected to local, essentially non-linear attachments," Journal of Sound and Vibration, vol. 264, no. 3, pp. 559-577, 2003.

[21] D. M. McFarland, L. A. Bergman, and A. F. Vakakis, "Experimental study of non-linear energy pumping occurring at a single fast frequency," International Journal of Non-linear Mechanics, vol. 40, no. 6, pp. 891-899, 2005.

[22] G. Kerschen, A. F. Vakakis, Y. S. Lee, D. M. McFarland, J. J. Kowtko, and L. A. Bergman, "Energy transfers in a system of two coupled oscillators with essential nonlinearity: 1:1 resonance manifold and transient bridging orbits," Nonlinear Dynamics, vol. 42, no. 3, pp. 283-303, 2005.

[23] Y.-W. Zhang, C. Wang, B. Yuan, and B. Fang, "Integration of geometrical and material nonlinear energy sink with piezoelectric material energy harvester," Shock and Vibration, vol. 2017, Article ID 1987456, 11 pages, 2017.

[24] H. Yao, D. Zheng, and B. Wen, "Magnetic nonlinear energy sink for vibration attenuation of unbalanced rotor system," Shock and Vibration, vol. 2017, Article ID 4132607, 15 pages, 2017.

[25] G. Bolar, A. Das, and S. N. Joshi, "Measurement and analysis of cutting force and product surface quality during endmilling of thin-wall components," Measurement, vol. 121, pp. 190-204, 2018.

[26] S.-M. Wang, C.-Y. Lee, H. Gunawan, and C.-C. Yeh, "An accuracy-efficiency-power consumption hybrid optimization method for CNC milling process," Applied Sciences, vol. 9, no. 7, p. 1495, 2019.

[27] T. Ding, S. Zhang, Y. Wang, and X. Zhu, "Empirical models and optimal cutting parameters for cutting forces and surface roughness in hard milling of AISI H13 steel," The International Journal of Advanced Manufacturing Technology, vol. 51, no. 1-4, pp. 45-55, 2010.

[28] A. Comak and Y. Altintas, "Mechanics of turn-milling operations," International Journal of Machine Tools and Manufacture, vol. 121, pp. 2-9, 2017. 